LCRL-CR-117769

S/C B235369

Strong Motion Duration and Earthquake Magnitude Relationships

Michael W. Salmon

Steven A. Short

EQE Engineering Consultants

Robert P. Kennedy

RPK Structural Mechanics Consulting

juste 1992

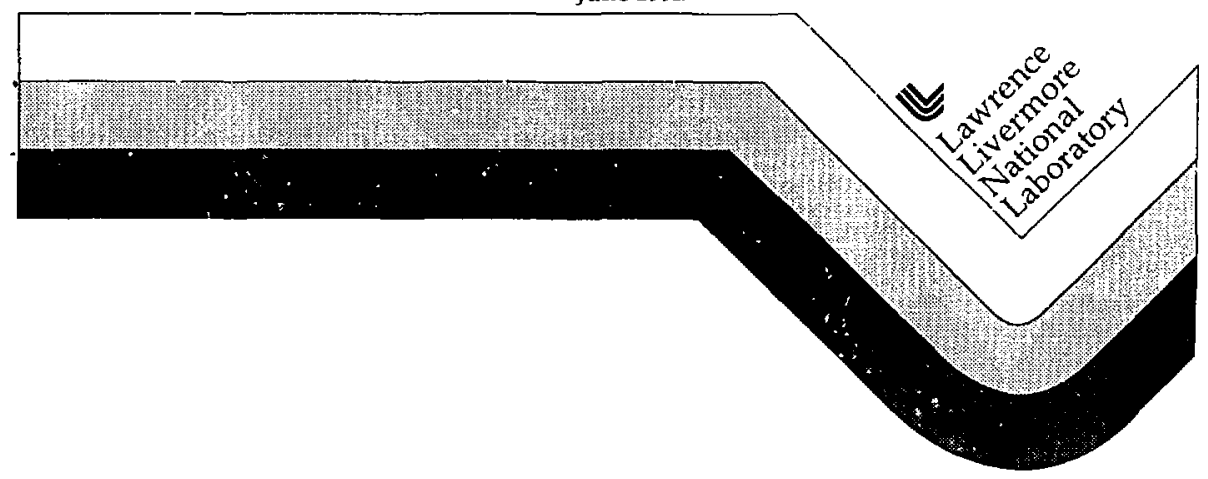




\section{DISCLAIMTR}

This document was prepared as an account of work sponsored by an agency of the United States Government. Neither the United States Governument nor the University a. California nor any of their employecs, makes any warranty. express or inplied, or assumes any legal liability or responsibility for the accuracy, completeness, or usefulness of any information. apparatus. pruducl. or process disclosed, or represents that its use would not infringe privately own:d rights. Reference bercin to any specific commercial products, process, or service by trade, nanne. urademark, manufacturer, or utherwise. does not necessarily canstilute ir imply its enjorsement, recommendation, or favoring by the United States Government or the Unjyersity of Californin. The VIL'ts and oninions of authors expressed herein do not necessurily state or reflect those of the United States government or the University of Californis. and shall not be used for advertising or ponduct endorsement purposes.

This work was performed under the auspices of the U1. S. Department of Energy by lawrence l.ivernore National Laboratory under contract No. $\$$ W. $740.5-\mathrm{Eng}-48$ 


\title{
Strong Motion Duration and Earthquake Magnitude Relationships
}

\author{
Prepared for \\ Assistant Secretary for Environment, Safety, and Health Orfice of Risk Analysis and \\ Technology U.S. Department of Energy
}

\section{Under Contract to}

Lawrence Livermore National iaboratory

University of California

Livermore, California 


\title{
Strong Motion Duration and Earthquake Magnitude Relationships
}

\author{
by \\ Michael W. Salmon \\ Stephen A. Short \\ EQE Engineering Consultants \\ Robert P. Kennedy \\ RPK Structural Mechanics Consulting
}

June 1992

\section{Introduction}

Earthquake duration is the total time of ground shaking from the arrival of seismic waves until the return to ambient conditions. Much of this time is at relatively low shaking levels which have little effect on seismic structural response and on earthquake damage potential. As a result, a parameter termed "strong motion duration" has been defitued by a number of investigators to be used for the purpose of evaluating seismic response and assessing the potential for structural damage due to earthquakes. Figure $I$ shows an example of an accelerogram, and the differences between the strong motion duration ard the total duration.

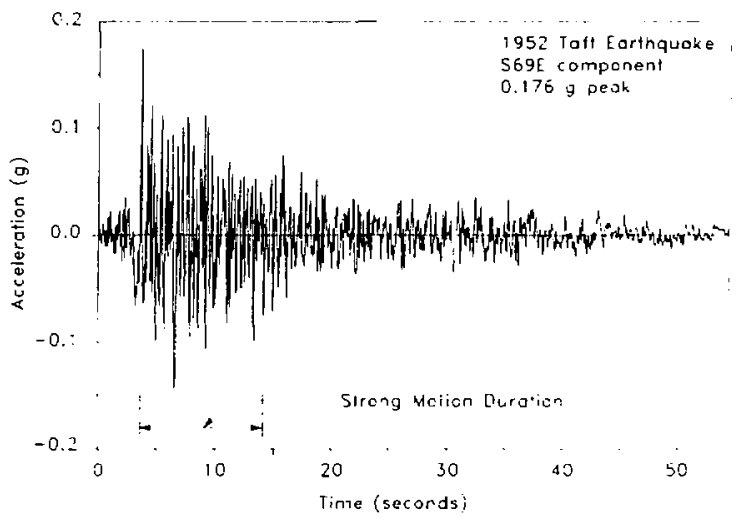

Figure I Strong Motion Duration 
For design, the duration of the design basis earthquake generally is not an issue since for response spectrum, equivalent static, and even time history methods of analyses, only the peaks of the response are used in developing design seismic forces. However, the duration of strong earhquake inotion is a significant parameter for earhquake damage potential when considering low cycle fatigue, soil liquefaction, soil settlement, and inelastic structural response. In addition. for one method of generating synthetic earthquake time histories, it is necessary to establish a time history envelope function consistent wid the strong motion duration of the potential carthquakes governing the design/evaluation level seismic loadings.

This report presents methods for determining strong motion duration and a time history envelope function appropriate for various evaluation purposes, for earthquake magnitude and distance. and for site soil properties. There are numerous definitions of strong motion duration (Refs. 3, 5 . $6,7,8,10,16$, and 17 ). For most of these definitions, empirical studies have been completed which relate duration to earthquake rnagnitude and distance and to site soil properties. Each of these definitions recognizes that only the portion of an earthquake record which has sufficiently high acceleration amplitude, energy content, or some other parameters significantly affects seismic response. Studies have been performed which indicate that the portion of an earthquake record in which the power (average rate of energy input) is maximum correlates most closely with potential damage to stiff nuclear power plant structures (Ref. 8). Hence, this report will concentrate on energy based strong motion duration definitions.

\section{Background}

Earthquakes are initiated by rupture and slippage along geologic faults. As a result, body waves aie emitted outward from the source of the earthquake (zone of energy release). Body waves are of two kinds: $P$ (primary, longitudinal, or compressional) and $S$ (secondary, transverse. or shear). Particle motion for $\mathrm{P}$-waves is back and forth along the direction of wave travel. $\mathrm{Par}$ ticle motion for $S$-waves is back and forth perpendicular to the direction of wave travel. Body waves generally arrive at a surface location along a nearly vertical wave path. This is because they originate from the earthquake source at d.pth and travel horizontally through decp, highly competent material and then vertically upward. When body waves reach the greund surface they originate surtace waves which travel parallel to the surface. There are many kinds of surface waves. Of greatest interest in earthquake engineering are $L$ (Love) and $R$ (Rayleigh) waves. Particle motion in L-waves is in a horizontal plane perpendicular to the direction of wave travel. In $R$-waves of a given frequency, particle motion is elliptical in vertical planes.

At an instrument location, P-waves are first to arrive. followed by $S$-waves and finally surface waves. As a result, earhquake acceleration records may be viewed as having three segments. The first segment represents the P-wave arrivals which are characterized by low amplitude. The second segment is mainly associated with direct $\mathbf{S}$-wave arrivals which have relatively high amplitudes and high frequencies. The duration of the direct $S$-wave segment is mainly controlled by the duration of rupture at the causative fault. There is continuation of P-wave arrival during the second segment of the motion. The last segment is closely related to the surface wave presenci or to the delayed indirect body wave arrivals and has low frequencies and anplitudes ranging from low to moderately high, depending on the local soil conditions, site lopography. and the distance from the zone of energy release along the fault. The end of the direct $S$-wave arrivals and the beginring of the surface wave arrivals are difficult to distinguish clearly and typically there is overlap of the second and third parts of earthquake records. Of the three signents, the first contains $P$-waves only: the second contains $P$ and $S$; and the third has some $P$ and mostly $S$. L. and R-?aves. 
Earthquake duration increases with increasing earthquake magnitude. When an earthquake is of a larger niagnitude, the dimensions of fault rupture is larger. Since the dislocation velocity does not change significantly with magnitude, the duration of fault rupture, which is closely related to the duration of the earthquake record, generally increases with increasing earthquake magnitude.

Earthquake duration also increases with increasing distance from the recording site to the zone of energy release of the causative earhquake. This phenomenon is due to the presence of slowly propagating surface waves arriving from long distance as well as of late :ime indirect body wave arrivals due to increased numbers of refractions, reflections, and scatterings of body waves over the longer travel path. Earthquake duration also is greater at soil sites than at rock sites. Earthquake records on soil sites have an additional long period portion not seen in rock records. This long period portion is associated with the difference in dynamic characteristics between hard and soft soils (high impedance ratio).

The generation of synthetic time-histories to match broad banded design spectra may follow two approaches. One approach is to use an actual earthquake time history which produces a response spectrum shape close to the required response spectrum. The Fourier phase spectrum from this time history may be retained and the Fourier amplitudes adjusted, frequency by frequency, ' rtil the resulting response spectrum closely envelopes the required response spectrum. The other approach uses a random Fourier phase spectrum and a deterministic time-envelope function. A typical time-envelope function as shown in Figure 2 consists of three porions: 1 , is the rise time, $t_{m}$ is the time of maximum power and is that portion which most closely corresponds to the strong motion duration, and $t_{d}$ is the decay time. In Philippacopoulos, 1989. Kennedy states that the rise and decay time durations are relatively unimportant but should typically be taken to be about $1 / 7$ and $5 / 7$ of $\mathrm{t}_{\mathrm{m}}$, respectively.

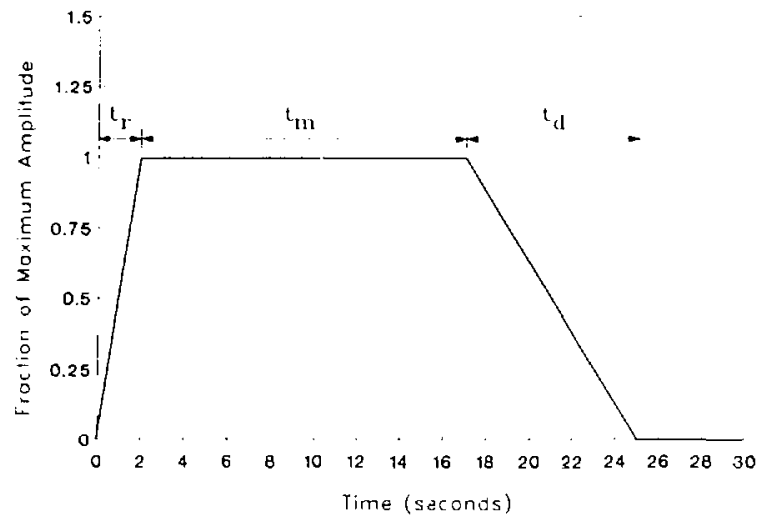

Figure 2 Duration Envelope Funcion 


\section{Strong Motion Duration Definitions by Various Investigators}

There are a number of definitions of strong motion duration which have been developed by many investigators. Each of these definitions is based upon the fact that the damage potential of an earthquake is a function of the energy of the earthquake, and that the majority of the total energy associated with any earthquake is contained in portions of the earthquake time history which is much shorter in time than the total duration. Probably the most common strong motion duration definition is that given by Trifunac-Brady (1975) who proposed a definition of strong motion duration based on a percentage of cumulative energy. It is defined as:

$$
T_{T \cdot g}=T_{\text {DQ }}-T_{\text {oos }}
$$

where $\mathrm{T}_{0.95}$ and $\mathrm{T}_{0.05}$ represent the times at which $95 \%$ and $5 \%$, respectively, of the cumulative energy are reached. Thus, this duration includes $90 \%$ of the total cumulative energy. The cumulative energy $I:\left(t_{1}\right)$ of an acceleration time history $A(l)$ at time, $t_{1}$ is given by:

$$
E(t,)=\int_{0}^{1} t^{\prime}(t) d t
$$

Alternative definitions of strong motion duration have been developed because it was judged that, for stiff structures ( 2 to $10 \mathrm{hz}$ ) such as those in nuclear power piants, Eq. 1 provides too long of an estimate of strong motion duration for many records. Many reeords contain a long tail of oscillatory ground motion with lesser acceleration at the end of the reeord which continues to input energy but at a substantially lesser rate than the earier portion of the racord. These definitions of strong motion ćuration are denoted, $T_{D}$, from NUREG/CR-5347 (Philippacopoulos, 1989) and, $T_{D}{ }^{\prime}$, from NUREG/CR-3805 (Kennedy, et, al., 1984) as described below.

$$
T_{D}=T_{D . r S}-T_{D 03}
$$

where $T_{0 \text { rs }}$ and $T_{0.05}$ are the times at which $75 \%$ and $S$, respectively. of tive cumulative energy are reached. Thus, this duration includes $70 \%$ of the total cumulative energy.

NLIREG/CR-3805 attempted to define a duration estinate which is directly related to damage for stiff engineered structures such as shear wall structures typically found in nuclear power plant sites. The study was conducted using the twelve earthquake time histories shown in Table 1. The time of maximum response for both elastic and nonlinear structure representative of degrading stiffness and degrading strength shear walis was considered. Four shear wall structure models with different initial elastic natural frequencies were used. Using the records shown in Table 1 , the time of maximum displacement response for elastic response, and for two levels of nonlinear response was determined. The uppor bound of maximum response was noted for the complete set of shear wall structure models and was compared to various tinies associated with percentages of the total cusulative energy. This study concluded that an upper bound on the time of maxinum response, $T_{4}$. can be reasonably approximated by:

$$
I_{\mathrm{u}}=\max \left\{\begin{array}{c}
r_{\mathrm{a}} \\
r_{p+\mathrm{a}}
\end{array}\right\}
$$


where: $\quad T_{0.75}$ is the time at which $75 \%$ of the cumulative energy contained in the accelerogram has been reached.

$T_{D a}$ is the time associated with the first zero crossing of the accelerogram following the maximum pos tive or negative acceleration.

and that the corresponding strong motion duration is then given by:

$$
T_{D}{ }^{\prime}=T_{\mu}-T_{0.0 \mathrm{~s}}
$$

This definition is slightly different than $T_{D}$, Eq. 3, recommended in NUREG/CR-5347 (Philippacopoulos. 1989). This definition may sometimes yield values of strong motion duration greater than those given by $\mathrm{Eq}$. 3 . When the peak giound acceleration occurs later in time than $T_{0.75}, T_{D}$ ' will be greater than $T_{D}$. This is seen in Table 1 for both the Olympia, 1949, and Pacoima Dam, 1971 records. In other cases, the two definitions yield the same duration value.

Table 1

Comparison of Duration Measures for Selected Input Accelerograms

\begin{tabular}{|c|c|c|c|}
\hline Earthquake Record (Component) & $\mathrm{T}_{\mathrm{n}}$ & $\mathrm{T}_{\mathrm{D}}$ & $T_{\mathrm{T}-\mathrm{B}}$ \\
\hline Taft, Kem. Co., 1952, (S69E) [M=7.7] & 10.3 & 10.3 & 28.1 \\
\hline Olympia, WA., 1949 (NB6E) [M=7.0] & 14.8 & 15.6 & 17.3 \\
\hline El Centro Array No. 12, Imperial Valley, 1979 (140) [M=6.9] & 9.6 & 9.6 & 18.6 \\
\hline El Centro Array No. 5, Imperial Valley, 1979, (140) [M=6.9] & 3.4 & 3.4 & 8.2 \\
\hline Pacoima Dam, San Fernando, 1971 (S14W) $[M=6.6]$ & 5.6 & 6.1 & 7.4 \\
\hline Hollywood Sinrege PE Lot, San Femando, 1971 (N90E) (M=6.6] & 5.4 & 5.4 & 11.7 \\
\hline Artificial, (R.G. 1.60) & 9.4 & 9.4 & 13.0 \\
\hline UCSB Goleta, Santa Barbara, 1978 (180) [M=5.1] & 3.0 & 3.0 & 9.7 \\
\hline Gilroy Array No. 2, Coyote Lake, $10.79,(050)[M=5.7]$ & 2.2 & 2.2 & 7.5 \\
\hline Cholame , sray No. 2, Parkfield, 1966, (N65E) [M=5.6] & 1.4 & 1.4 & 9.2 \\
\hline Gavilan College, Hullister, 1974 (S67W) $[M=5.2]$ & 1.1 & 1.1 & 1.6 \\
\hline Malendy Ranch barn, Bear Valley, 1972 (N29W) $[M=4$ 기 & 0.8 & 0.8 & 2.6 \\
\hline
\end{tabular}

Magnitude, $M=M_{3}$ from 5.9 to 8.0; $M_{L}$ below 5.9

Unlike the NUREG/CR-5347 definition of strong metion duration, $T_{D}$, most of the other proposed definitions for duration commonly used in engineering practice do not attempl to relate the definition of duration to damage. Most definitions for duration are expressed in terms of some percentzge of the total energy contained in the accelerogram as measured by the Arias intensity (Arias, 1970). Other definitions in use are based on the time berween the first exceedance of some PGA level (typically $0.05 \mathrm{~g}$ ) and the last exceedance of this level, or upon the time at which the acceleration exceeds some set leve!.

Esteva and Rosenblueth (1964) defined the strong notion duration as the duration of an equivalent ground motion with uniform intensity per unit time. They proposed one of the first empirical relationships for predicting duration for a given magnitude and site to source distance. 
Bolt (1973) defined "bracketed duration" of a record, as the elapsed time between the first and last acceleration excursions greater than a given level. He proposed the use of 0.05 or 0 . ig acceleration levels. This detinition requires that the absolute values of the acceleration of a record exceed some level. Therefore, records having a reak acceleration smaller than $0.05 \mathrm{~g}$ have zero duration.

Housner (1965; proposed a conservative relationship from which to estimate the upper bound duration of ground motion. This upper bound estimate was based on enveloping the strong motion durations of 16 horizontal accelerograms from pre-1957 west coast U.S. earthquakes. Strong motion duration was not defined definitively in Housner (1965); however, Frifunac (1975) reports that results from Bolt (1973) for the bracketed duration of acceleration greater than $0.05 \mathrm{~g}$ yield essentially the same durations as repored in Housner (1965).

Hisado and Ando (1976) defined the duration of ground motion to be the total time from the beginning of the record to the time when the amplitude of the wave becomes equal to one-tenth of the peak acceleration.

Vanmarcke and Lai (1980) proposed a definition of strong motion duration, $S_{0}$, as the time in which the total energy of a ground motion record is distributed uniformly at constant average power. By this definition, $S_{0}$ is given in :erms of the total cumulative energy, $E_{m}$ (determined from Eq. 2 integrated over the entire duration), maximum ground acceleration, $p g a$ and the predominant period of the strong motion phase of the earthquake motion. $T_{*}$ (comnonly ranges from 0.2 to 0.6 seconds, determined by counting zero crossings of a record) as:

$$
S_{0}=\left[5.42-2 \ln T_{0}+2 \ln \left(\frac{E_{m}}{p g a^{2}}\right)\right] \frac{E_{m}}{p g a^{2}}
$$

McCann and Shah (1980) defined the strong motion phase of an accelerogram as that part of the time history that exhibits a "consistent" root mean square ( $\left.r^{\prime} n s\right)$ or power level. Th.ey further proposed that the intensity of strong ground shaking could be realistically represented by a statistical average such as the root mean square, and the duration over which the rms persists. A cumulative root mean square function forms the basis for McCann and Shah's duration defirition. For a discretized accelerogram containing $m$ points, the rms is determined for each point 11 , where $n$ varies from 0 to $m$ :

$$
r m s_{n}=\sqrt{\frac{1}{n} \sum_{1=1}^{n} a_{1}^{2}}
$$

The beginning of the strong motion is obtained by forming the cumulative mis function of the time reversed accelerogram and noting the time at which the cumulative rms function takes on a negative slope. The end of the strong ground motion is obrained in a similar manner using the original time history of the accelerogram.

Theofanopulos-Watabe (1989) proposed a definition of strong motion duration based upon the distribution of wave energy over the time history, as opposed to the cunulative energy distribution defined by Eq. 2. The following function of time was proposed:

$$
E(t)=l(t+d l)-l(t)
$$


where $d t$ is the time increment and $/(t)$ is the Arias intensity function (Eq. $2 \times(\pi / 2 g)$ ) with integration limits from 0 to $\ell$.

This function represents the energy added at each time increment of the earthquake motion. The weighted by $E(t)$ average value $(\mu)$ of $t$ was proposed as follows:

$$
\mu=\sum_{u=1}^{N} u \cdot d t \cdot E(u \cdot d t) / \sum_{u=1}^{N} E(u \cdot d t)
$$

The weighted by $E(1)$ standard deviation $(\sigma)$ of $\&$ was proposed as follows:

$$
\sigma=\left[\sum_{v=1}^{N}(v \cdot d t-\mu) E(v \cdot d t) / \sum_{v=1}^{N} E(v \cdot d t)\right]^{1 / 2}
$$

where $N$ is the total number of data points, $N=T_{m} / d t$ and $T_{m}$ is the total duration of the record.

The end of the strong motion proposed by Theofanopulos-Watabe (1989) is obtained as:

$$
T_{2}=1:+\sigma
$$

The strong motion duration is the difference between the time at which a threshold value of $E(T)$ is exceeded and $T_{2}$, the end of strong motion. Theofanopulos-Watabe took this threshold value as equal to the value of $E(T)$ at the end of the strong motion interval $E\left(T_{2}\right)$

NUREG/CR-3805 (Ref. 8) concluded that the portion of an earthquake record in which the power (rate of energy input) is maximum correlates most closely with rotential damage to stiff nuclear puwer plant structures. The Trifunac-Brady, NUREG/CR-5347, Esteva-Rosenblueth, Vanmarcke-Lai, McCann-Shah, and Theofanopulos-Watabe strong mction duration definitions are all based on the energy content of an earthquake record. Furthermore, all of these definitions except Trifunac-Brady attempt to represent the time associated with maximum power. These energy based strong motion duration definitions are considered in the remainder of this report.

\section{Empirical Strong Motion Duration Relationships}

Studies of past earthquake time histories have been performed to develop relationships between earthquake magninde and strong motion duration using many of the strong motion definitions described above. Theofanopulos and Watabe (1989) conducted extensive empirical studies using the Trifunac-Brady, Theofanopulos-Watabe, and McCann-Shah strong motion duration definitions. Theofanopulos and Watabe developed the following empirical equation relating strong motion duration, $D$ (seconcis), earthquake magnitude, (M), distance to causative fault, $R(\mathrm{~km})$, and site soil conditions, $S(0,1$, and 2 for hard, intermediate, and soft soil, respectively):

$$
D=a+b e^{c H l}+d R+e S
$$

$a, b, c, d$, and e are empirical constants as given in Table 2. The distance to causative fault, $R$, is defined as the shortest distance between the site and the surface projection of the fault. Hard soil or rock is defined to be that with shear wave velocity of $3500 \mathrm{fps}$ (1100 mps) or greater. Soft soil sites are characterized by deep alluvium (depth gredter than $16 \mathrm{~m}$ ) or otherwise soft sedinentary deposits. Intermediate sites are those which can be classified as neither hard nor soft. Note that Dobry. 1978 has also developed empirical relations for the Trifunac-Brady definition but the 
Theofanopulos-Watabe work is more extensive and more recent. Esteva and Rosenblueth had developed one of the earliest magnitude-duration relaitins in $1964 . i$, is relation which was independent of soil conditions fits into the format of Eq. 12 with the constants given in Table 2 . Vanmarcke and Lai studied 140 earthquake records of which 118 were frem soil sites. They developed the following relations for their definition of duration, $S_{0}$ :

$$
\begin{aligned}
& S_{0}=4.4(M-4.2) \\
& S_{0}=0.115(R+.30)
\end{aligned}
$$$$
\text { for all distances }
$$

for all magnitudes

Table 2

Empirical Constants for Strong Motion Duration Equation

\begin{tabular}{|c|c|c|c|c|c|}
\hline Strong Motion Duration Definition & $\mathrm{a}$ & $\mathrm{b}$ & $\mathrm{c}$ & $d$ & $\mathrm{~d}$ \\
\hline \hline Trifunac-Brady & $2.26 \mathrm{c}$ & 0.02489 & 0.860 & 0.05335 & 2.883 \\
\hline Theofanopalos-Watabe & -13.230 & 4.36900 & 0.253 & 0.03673 & 2.121 \\
\hline McCann-Shah & -2.707 & 0.02811 & 0.757 & 0.03290 & 1.224 \\
\hline Esteva-Rosenblueth & 0 & 0.02 & 0.74 & 0.3 & - \\
\hline
\end{tabular}

Strong motion durzition vs. magnitude relations for all the energy based definitions except that from NUREG/C? -5347 (not available) are shown in Figure 3. The strong motion values shown in the figure are for a rock site located in the near field of the causative earthquake $(15 \mathrm{~km}$ from the earthtquake source) with the exception of Esteva-Rosenblueth which is independent of soil conditions and Vanmarcke-Lai which is independent of both distance and soil corditions. Figure 3 demonstrates that strong molion duration increases with increasing earhquake magnitude.

The Esteva-Rosenblueth, Vanmarcke-Lai, McCann-Shah, and Theofanopulos-Watabe strong motion duration definitions are based on the time of maximum power and, thus, would be appropriate to use for the design/evaluation of stiff nuclear power plant structures. The Trifunac-Brady definition is expected to give durations longer than the time associated with maximum power including most of the earthquake record energy content $(90 \%)$. Earthquake magnitudes governing design earthquake ground motion generally range from a lower bound magnitude of $5-5.5$ to an upper bound magnitude of 7.5 - ?. From Figure 3 and considering durations by the EstevaRosenblueth, Vanmarcke-Lai, MicCann-Shah, and Theofanopulos-Watabe definitions, it may be seen that for the magnitude $5 \cdot 5.5$ :ange, durations range from about 3 to 5 seconds and, for the magnitude 7.5 - 8 range, durations ange from about 10 to 20 seconds. Note that durations by th: Vanmarcke-Lai and Theofanopul's-Watabe definitions agree closely.

To illustrate the effects of distarse and soil conditions on nugnitude, strong motion duration vs. ear:'?quake magnitude by the Trifunac-Brady and Theofanopulos-Watabe definitions are p! sted in Figures 4 and 5 respectively. Each figure includes rock and soft soil conditions and near-field $(15 \mathrm{~km})$ and distant $(50 \mathrm{~km})$ earthquake locations. Figures 4 and 5 demonstrate that by either defi. nition of strong motion duration, the soil conditions have a significant effect on duration and the distance has a less significant effect. The effect of increased distance from $15 \mathrm{~km}$ to $50 \mathrm{~km}$ is that strong motion duration increased by about 1.5 seconds at all magnitudes for both definitions. The 
effect oi going from a rock site to a soft soil site was an increase in strong motion curation at all magnitudes of about 6 seconds for the Trifunac-Brady definition and of about $4 \mathrm{~s}$.conds for the Theofanopulos-Watabe definition. These figures demonstrate that duration increases with; reasing distance and that duration for rock sites is lower than that for soil sites. The qualitative reasons for these observations were discussed previously in Section 2.

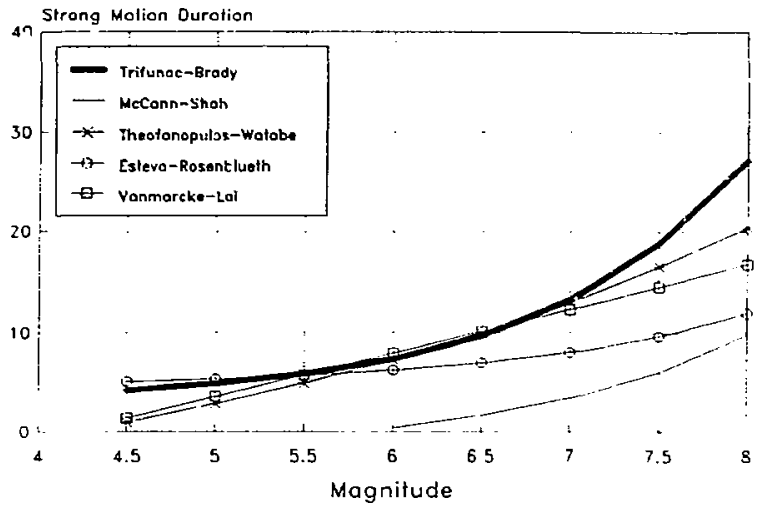

Figure 3 Strong Motion Duration vs. Earthquake Magnitude for Energy-Based Duration Definitions (Rock site, $15 \mathrm{~km}$ )

Empirical studies of the NUREG/CR-5347 duration Jefinition, ?. which includes $70 \%$ of the cunulative energy (Eq. 3) are not available as they are for Trifunac-3ridy. Thect nnopulosWatabe, McCann-Shah, Vanmarcke-Lai, and Esteva-Rosenblueth. Values of strong motion duration, $T_{D}$, computed in accordance with Eq. 3 are available for the records summarized in Table 1 . In addition, $T_{D}$ values have been computed for lecords from the 1989 Loma Prieta earahquake ind other earthquakes as repotted in Geomatrix, 1991. The $T_{n}$ values from Table $l$ and from Geomatrix, 1991 are plotted as a function of magnitude in Figu. $=0$. Also plotted on this figure are the strong motion duration vs magnitude relations for the other definitions which attempt to use the time associated with maximum power (rock site at $15 \mathrm{~km}$, where applicable). Even though the earhçuake data are from a variety of soil conditions and distances, durations from this data tend to be somewhat lower than from the empirically developed relations (with the exception of McCannShah). It should be noted that the Loma Prieta data at Magnitude 7 is anomalously low due to the particular fault nupture characteristics of this earthquake. In addition. these are nuch fewer data points than were used to establish the relations in Eqs. 12 and 13 and Table 2. Therefore, there is insufficient data available to establish a reliable relation for $T_{b}$ as a function of earhquake magnitude. An approuch for establishing such a relationship will be proposed in Section 6. 


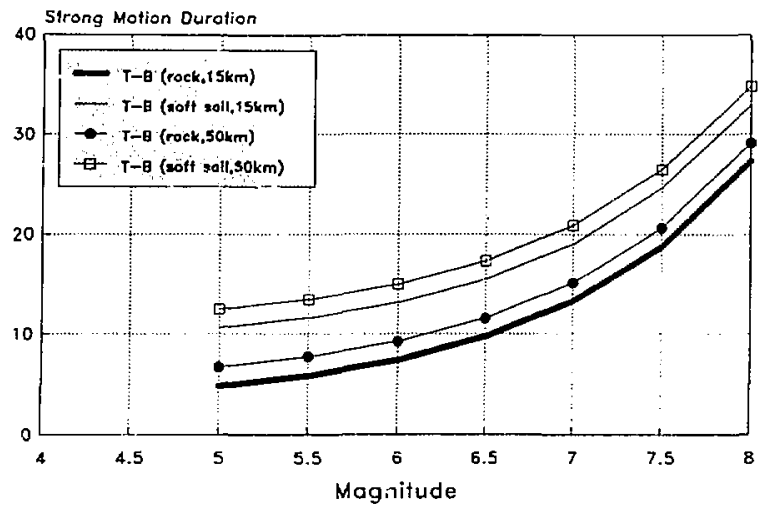

Figure 4 Trifunac-Brady Strong Motion Durstion vs. Magnitude

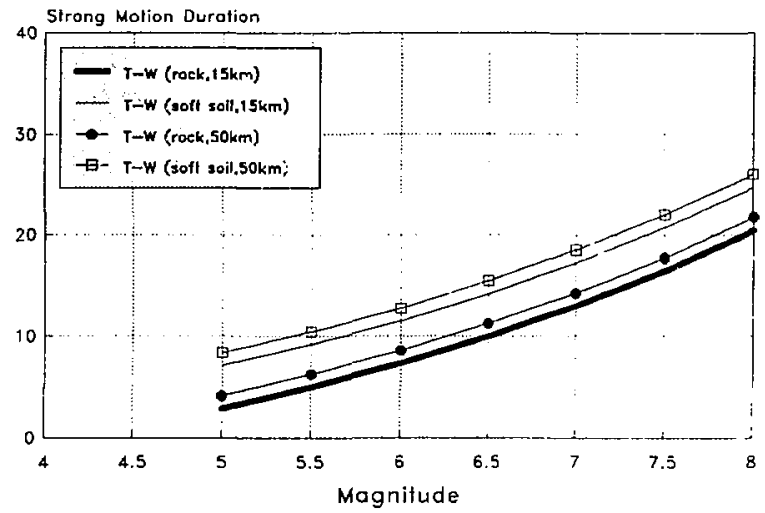

Figure 5 Theofanopulos-Watabe Strong Motion Duration vs. Magnitude 


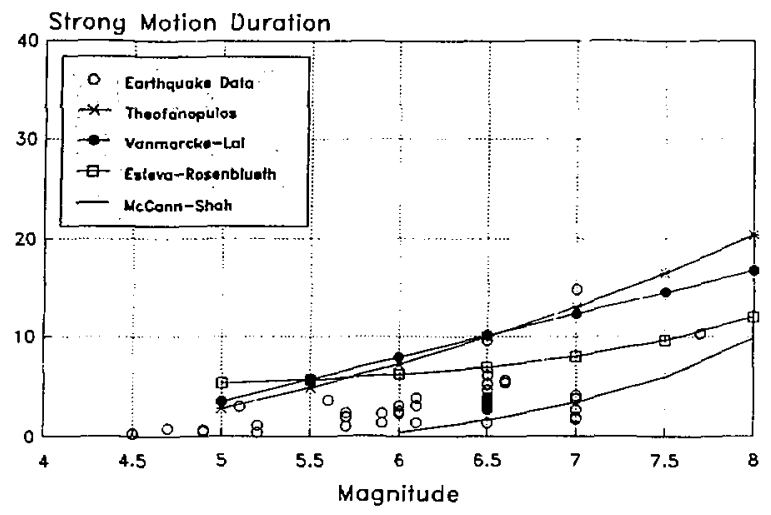

Figure 6 Strong Motion Duration by 70\% Cumulative Energy Definition vs. Empirical Duration Relations by Other Energy-Based Definitions

\section{Duration Requirements for Seismic Analyses of Nuclear Power Plants}

Section 3.7.1. (11.1 b) of NUREG-0800 provides the minimum strong motion duration requirements for linear structural analyses, using site-independent response spectra such as Regulatory Guide 1.60. The strong motion duration requirements in NUREG-0800 are as follows:

1. The total time duration should be hetween 10 and 25 seconds.

2. The corresponding stationary phase strong-motion duration should be between 6 seconds and 15 seconds.

3. If site-specific information indicates duration estimates outside these bounds, the site-specific values should be used.

The strong motion duration definition used for commercial nuclear power plants is one that includes the time of maximum power. Duration is defined in this manner because it was felt that Trifunac-Brady and other similar "long" definitions of duration were overly conservative. It has been shown that there is a portion of many records which can extend for a long period of time in which the last 20 to $25 \%$ of the earthquake energy is contained but which is a low acceleration levels and which will have very litle effect of the seismic response of nuclear power plant type structures. Furthermore, in NUREG/CR-5347 (Philippacopoulos, 1989) Kennedy gives two reasons for not using artificial time histories with strong motion duration in excess of 15 seconds. or total durations longer than 25 seconds. These are:

1. The high frequency power can be concentrated near the start of the record with the low frequency power concentrated near the end of the record. In this way, the high and low frequency modes of a $5 \%$ or more damped structure will not combine 
because the high frequency response is damped out before the low frequency response becomes strong. Thus, combined response can be severely unconservatively biased.

2. If random phasing is assumed for all Fourier harmonics, then modes have an increased probability of coming into essentially worst-case phasing (absolute sum combination) at some time as strong motion durations are increased to very long times. Thus, combined resporises can be scverely overestimated when excessively long strong motion durations are used.

The SRF provisions primarily apply to the time duration envelope parameters as shown in Figure 2 which are used to develop artificia! accelerograms. For this purpose, a "short" duration definition such as that which from NUREG/CR-5347 ( $70 \%$ on the cumulative energy of the record) is most appropriate as neither such a definition nor the time duration envelope function include a long tail of low acceleration input. This provides a reasonable definition of effective strong motion duration for stiff structures (2 to $10 \mathrm{hz}$ ). Such "short" duration definitions include NUREG/CR5347, Theofanopulos-Watabe, McCann-Shah, Vanmarcke-Lai, and Esteva-Rosenblueth. Studies which have correlated strong motion duration defined in this manner with earthquake characteristics such as magnitude, distance from earthquake source to the site, and site soil conditions have been performed for all definitions except that from NUREG/CR-5347 (Eq. 3). However, the means of relating these definitions to the parameters of the time envelope function (Figure 2) have not been performed. In the following section, an approach for estimating sizong motion duration corresponding to $70 \%$ of the cumulative energy and of estimating duration invelope function parameters as a function of earthquake and site characteristics is presented.

\section{Approach for Estimating NUREG/CR-5347 Duration and Duration Envelope Parameters as a Function of Magnitude}

The Trifunac-Brady, Vanmarcke and Lai, and NUREG/CR-5347 strong motion duration definitions are all based on relatively simple expressions related to the energy content of an earthquake record as given by Eq. 2 . In addition, it is assumed that the parameters defining the duration envelope function shown in Figure 2 can be related to the energy content. Also, it is useful that there are empirical studies relating duration by the Trifunac-Brady and Vanmarcke and Lai definitions to earthquake magnitude and other characteristics. Using the information listed above, an approach for estimating NUREG/CR-5347 duration and duration envelope parameters as a function of magritude will be developed in this section. This duration estimation approach is based on the following assumptions:

1. Consider the duration envelope function as shown in Figure 2. Assume this to be an acceleration vs. time function from which a parameter proportional to cumulative earthquake energy by utilizing $\mathrm{Eq} .2$ can be calculated.

2. For typical duration envelope functions [i.e., time of maximum amplitude, $t_{m} ; t_{s}=$

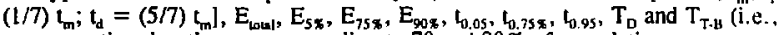
strong motion durations corresponding to 70 and $90 \%$ of cumulative energy. respectively), and $S_{0}$ (Vanmarcke-Lai duration) will be computed. It is assumed that these computed values are proportional to corresponding values for actual earthquake records. 
3. The Vanmarcke-Lai and Trifunac-Brady strong motion duration definitions are evaluated in this section for earthquake records idealized by the duration envelope function. The empirical duration-magnitude relation for $S_{0}$ (Vanmarcke-Lai) is independent of distance and site conditions (Eq. 13a). The empirical durationmagnitude relation for $\mathrm{T}_{\mathrm{T}-\mathrm{B}}$ (Trifunac-Brady) depends on both distance and site conditions (Eq. 12). When $\mathrm{T}_{\mathrm{T} \cdot \mathrm{B}}$ is evaluated from the duration envelope function, near field (15km) and rock site conditions are assumed.

4. The duration enveivje function as shown in Figure 2 is only appropriate for earthquake records which do not have long tails of low acceleration ground motion oscillations. Dobry, et.al., 1978 and others suggest that these long tails are caused by amplification of the soil of multi-path body wave arrivals and by surface wave effects. These phenomena are most significant at soil sites and/or when the ear thquake source is very distant from the site. Assume that earthquake records mieasured in the near field of the earthquake source are predominantly the direct shear wave arrival segment with a minimum of surface wave input and contributions due to refractions, reflections, scatterings, and high impedance ratio effects. As a result, a rock site and near field $(15 \mathrm{~km})$ conditions are judged most appropriate for relating $T_{T \cdot B}$ to the envelope function.

5. Assume that a relation between the NUREG/CR-5347 duration, $T_{D}$, and earthquake magnitude can be estimated from the Trifunac-Brady duration, $\mathrm{T}_{\mathrm{T} \cdot \mathrm{B}}$, vs. magnitude empirical relation by using the near-field $(15 \mathrm{~km})$, rock site relation and scaling this relation by a scale factor, $S F$, which is the ratio of $T_{D} / T_{T-B}$ as derermired from the duration envelope calculations (Item 2 above).

6. Assume that $T_{T \cdot B}, T_{D}$, and $S_{0}$ can all be related to the time of maximum amplitude, $t_{m}$ from the duration envelope calculations (Item 2 above). From these relations, $t_{m}$ may be estimated as a function of earthquake magnitude.

Duration envelope function calculations using the assumptions listed above are presented in the Appendix to this report. The results of these calculations for maximum energy content, $\mathrm{E}_{\mathrm{n}}$, time at which $5 \%, 75 \%$, and $95 \%$ of the total cumulative energy, $t_{0.05}, t_{0.75}, t_{0.95}$, Trifunac-Brady duration, $T_{T \cdot B}, N U R E G / C R-5347$ duration, $T_{D}$, and Vanmarcke-Lai duration, $S_{p}$, are:

$$
E_{m}=A_{m}^{2}\left(t_{r} / 3\right)+A_{m}^{2}\left(t_{m}\right)+A_{m}^{2}\left(t_{d} / 3\right)=1.286 i_{m}^{2} l_{m}
$$

\begin{tabular}{|c|c|}
\hline$t_{0.05}=0.159 t_{m}$ & $T_{T \cdot d}=1.235 t_{m}$ \\
\hline$t_{0.75}=1.059 t_{m}$ & $T_{D}=0.900 t_{m}$ \\
\hline$t_{0.05}=1.394 t_{m}$ & $S_{0}=1.286 t_{m}$ \\
\hline
\end{tabular}

The values summarized above are illustrated in Figure 7. For the typical duration envelope function [i.e., time of maximum amplitude, $\left.t_{m} ; t_{r}=(1 / 7) t_{m} ; t_{d}=(5 / 7) t_{m}\right], t_{0.05}$ and $t_{0.25 x}$ fall within the maximum amplitude region and $t_{0.9 s}$ falls within the decay region. $T_{D}$ is significantly shorter than both $T_{T \cdot B}$ and $S_{0}$, where $T_{D}$ is shoner than $t_{m}$ and $S_{0}$ is longer than $t_{m}$. From the relations tabulated above, it may be shown that $T_{v}=0.7 S_{0}$, which is reasonable since $T_{D}$ includes $70 \%$ of the total energy and $S_{\alpha}$ includes $100 \%$ of the energy. 


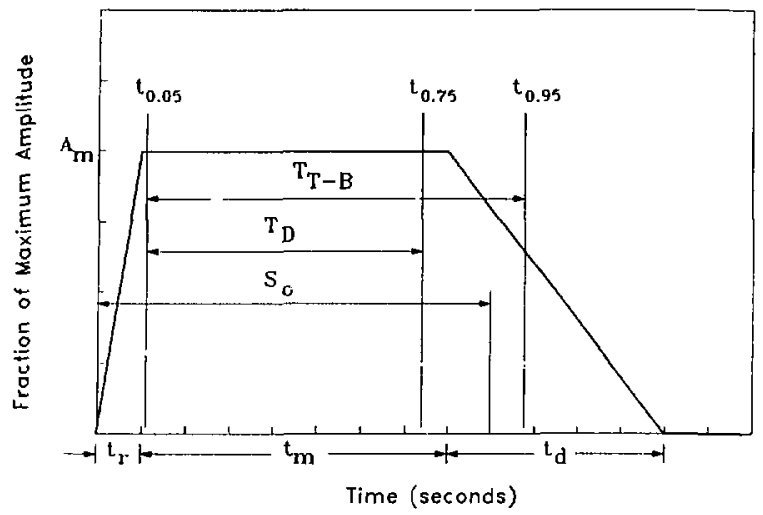

Figure 7 Relation Between Duration Envelope Function and Several Strong Motion Duration Definitions

Using tise values given above, the duration vs. magnitude relation given by Eq. 12 (with Trifunac-Brady coefficients, $R=15 \mathrm{~km}$, and $S=0$ [rock]) can be modified by scale factor, $S F$, to provide the follewing NUREG/CR-5347 duration vs. magnitude relationship:

$$
\begin{aligned}
& T_{0}=S F\left(a+b e^{e \mu}+d(15)+e(0)\right) \\
& T_{0}=S F\left(2.201+0.02489 e^{0.8604}+0.05335(15)\right) \\
& T_{0}=S F\left(3.001+0.02489 e^{0.8604}\right)
\end{aligned}
$$

Basea on the information summarized above and developed in the Aprondix, the scaic factor, SF. to be used in Eq. 14 is $T_{D} / T_{T-B}=0.900 / 1.235=0.729$. Therefore, a candidate prediction equation for $T_{D}$ is:

$$
T_{D}=2.187+0.01814 e^{0.860 \mathrm{~N}}
$$

Alternatively, $T_{D}$ as a function of earthcuake magnitude may be estimated from the Vanmarcke-Lai relation (Eq. 13) using that $T_{D}=0.7 S_{0}$. This results in:

$$
T_{0}=3.08(A t-4.2)
$$

Duration values from Eqs. 15 and 16 as a function of earthquake magnitude are ploted in Figure 8 along with values from the limited actual earthquake data for which durations by the NUREG/CR-5347 definition have been computed. Equations 15 and 16 produce estimates for $T_{0}$ which are in close agreement except in the 7.5 to 8 magnitude range where the Eq. 15 values are larger. Eq. 15 is based on the Trifunac-Brady empirical relation which rises more rapidly at higher magnitudes than any of the other relations. These equations produce duration values which: 
are ogenerally above the available data. Equations 15 and 16 result in duration-magnitude relations which are generally similar to relations for ather duration definitions which correspond to the time of marimum power with the exception of the McCann-Shah definition which is significantly lower than the other definitions (compare with Fig. 6).

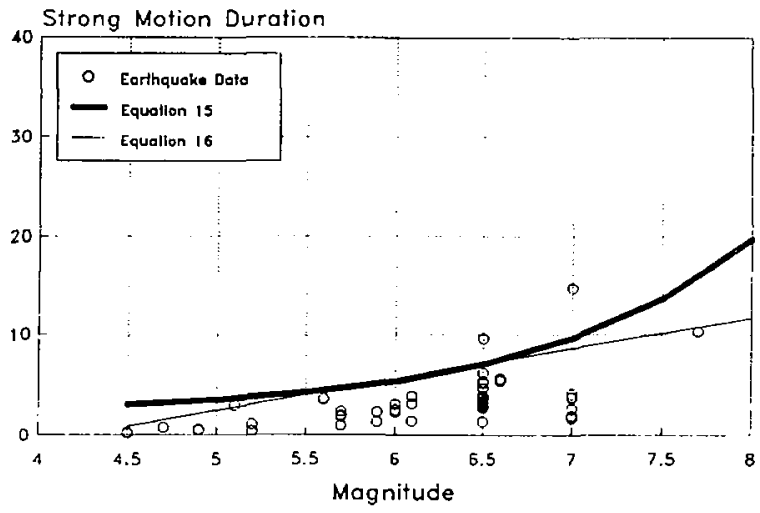

Figure 8 NUREG/CR-S347 Duration-Magnitude Relation Estimated
from Trifunae-Brady (Eq. 15) and from Vanmarcke-Lai (Eq. 16)
Based on Duration Envelope Calculation

Also using the values given above, $t_{m}$, for the duration snvelope function is equal to $(1 / 0.900) \mathrm{T}_{\mathrm{D}}=1.111 \mathrm{~T}_{\mathrm{b}}$ and $(1 / 1.286) \mathrm{S}_{\mathrm{o}}=0.778 \mathrm{~S}_{\mathrm{o}}$. From these expressions $\mathrm{t}_{\mathrm{m}}$ as a function of earthquake magnitude can be estimated from Eqs. 15 (NUREG/CR-5347) and 13 (Vanmarcke-Lai) as follows:

$$
\begin{aligned}
& t_{m}=2.430+0.02016 e^{0.800 M} \\
& t_{m}=3.422(M-4.2)
\end{aligned}
$$

Time of maximum amplitude, $t_{m}$, for a duration envelope function as shown in Figures 2 and 7, as determined from Eqs. 17 and 18 are plotted in Figure 9 . Figure 9 illustrates that $t_{m}$ determined from either the NUREG/CR-5347 (Eq. 16) or Vanmarcke-Lai (Eq. 17) strong motion duration definitions are very similar except at very high magnitudes. Using either relationship to obtain $t_{a,}$, rise time and decay time, $t_{r}$ and $t_{d}$, are then determined as recommended by Kennedy in Philippacopoulos, 1989, to be about $1 / 7$ and $5 / 7$ of $t_{m}$, respectively. 


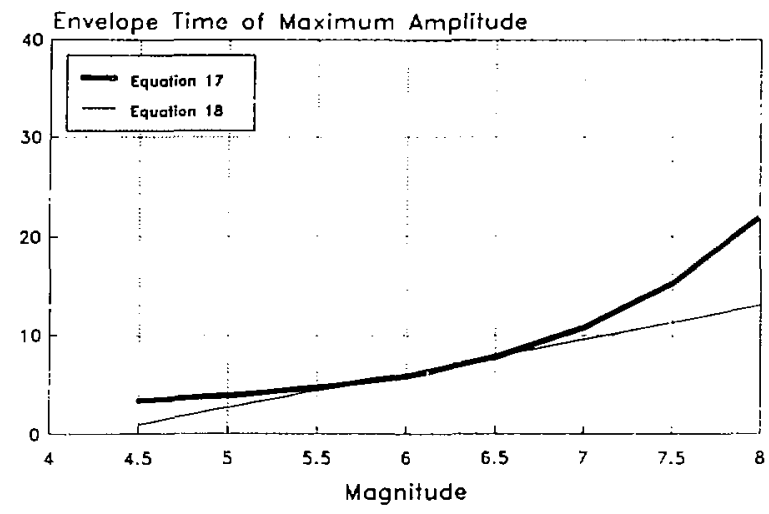

Figure 9 Envelope Function Time of Maximum Amplitude, $t_{\text {, }}$ as Delermined from Duration Envelope Calculations

\section{Recommended Strong Motion Duratiort Relationship}

In Section 6, equations have been developed which relate strong motion duration defined to be the time over which the power of an earthquake record is near its maximum in accordance with NUREG/CR-5347 with magnitude of the causarive earthquake. This definition of strong motion duration, $T_{0}$, begins when the cumulative energy of the earthquake record is at $5 \%$ of the total energy and ends when the cumulative energy is at $75 \%$ of the total energy. This definition is judged to be most closely correlated to potential seismic damage to stiff, nuclear power plant type tructures.

It should be noted that these equations are strongly based on a number of assumptions. An important assumption in developing Equation 15 is that $T_{D}$ is primarily due to the direct shear wave arrival segment of earthquake ground motion with little contribution from later time arrivals of surface waves and refracted, reflected, and scattered shear waves. It is further assumed that earthquake records from rock sites in the near field of the earthquake are due primarily to these direct shear wave arrivals. As a result of this latter assumption, empirical studies of strong motion duration by the Trifunac-Brady definition which includes $90 \%$ of the cumulative energy, $T_{T-3}$, for rock sites in the near field $(15 \mathrm{~km})$ have been used as one basis for estimating NUREG/CR-5347 duration, $T_{\mathrm{D}}$, as a function of earthquake magnitude (Equation 15). The above assumptions lead to the conclusion that $T_{D}$ depends only on magnitude and not on distance to causative fault or on site soil properties. The other equation developed for estimating $T_{D}$ is based on scaling the empirical relation between the Vanmarcke-Lai definition of duration and magnitude. The Vanmarcke-Lai duration is the time over which the total energy is uniformly distributed. $T_{D}$ is the time over which $70 \%$ of the total energy is uniformly distributed such that scaling the Vanmarcke-Lai relation by 0.7 is the basis for the other equation (Equation 16). Another significant assumption in developing both of these duration estimation equations has been that cumulative energy estimates can be made from the duration envelope function. 
For the evaluation of seismic response of stiff nuclear power plant type structures, Eqs. 15 and 16 provide reasonable methods of estimating strong motion duration, $T_{p}$. As shown in Figure 8, these equations agree closely except at very high earthquake magnitudes, they provide durationmagnitude relations that are similar to other energy based duration definitions, and they generally provide; duration values larger than the limited data for which $T_{D}$ values have been computed. For evaluation purposes in which the total number of cycles are of greater importance even though they may be of lesser amplitude, the Trifunac-Brady duration, $T_{T \cdot B}$, may be determined as a function of earthquake magnitude, distance to causative fault, and site soil properties from Eq. 12 and Table 2 empirical constants. Eq. 12 and Table 2 also provides information to evaluace strong motion duration by the Theofanopulos-Watabe, McCann-Shah, and Esteva-Rosenblueth definitions if those definitions are judged to be appropriate for the specific evaluation purposes considered.

Equations 15 and 16 imply a great deal more accuracy than exists in the estimation of NUREG/CR-5347 strong motion duration, $T_{D}$, with nıagnitude. As a result, it is judged that the duration-magnitude relation given in Table 3 is appropriate for evaluation of stiff nuclear power plant structures. These duration values are intended to correspond to the definition of strong motion duration as given in Eq. 3 and designated $T_{D}$. The recommended values are provide: for ranges of magnitudes and are about the average values from Eqs. 15 and 16 . These values are appropriate as one means for selecting actual earhquake time histories to be used for seismic evaluation or for developing artificial input time histories by the approach in which the Fourier phase spectrum is retained and the Fourier amplitudes are adjusted to match the desired input response spectrum. Note that durations as defined and specified herein must be used in a consistent manner when evaluating PSD functions and Fourier amplitudes of earthquake time histories. The recommended $T_{D}$ vs. magnitude relation is illustrated in Figure 10 along with the earthquake data for which $T_{D}$ values have been computed, and the Eq. 15 and 16 values.

For the approach for generating synthetic earthquake time histories in which a random Fourier amplitude spectrum and a duration envelope function (Figures 2 and 7 ) is employed, recommended values for time of maximum power, $t_{m}$, for rise time, $t_{r}$, and for decay time, $t_{d}$, are provided in Table 4. The recommended value! for $t_{m}$ were developed from the average values determined for Eqs. 17 and 18 as showa in the talie. The recommended time of maximum power. $t_{m}$, values as a function of magnilude are illustrated in Figure 11 along with values from Eqs 17 and 18. Note that recommended values of $t_{m}$ are less than the upper bound of 15 seconds from the Standard Review Plan (SRP) at all magnitudes. The recommended values of $\mathrm{t}_{\mathrm{m}}$ are below the lower SRP bound of 6 seconds for magnitudes less than 6 . 
Table 3

$T_{D}$ vs. Earthquake Magnitude

\begin{tabular}{|c|c|c|c|}
\hline Magnituuie & $\begin{array}{c}T_{\mathrm{D}} \text { from } \\
\text { Eq. } 15\end{array}$ & $\begin{array}{c}T_{\mathrm{D}} \text { from } \\
\text { Eq. } 16\end{array}$ & $\begin{array}{c}\text { Recommended Strong Motion } \\
\text { Duration, } T_{\mathrm{D}} \text { (sec) }\end{array}$ \\
\hline $7.5-8$ & 16.7 & 10.9 & 14 \\
$7-7.5$ & 11.7 & 9.4 & 11 \\
$6.5-7$ & 8.3 & 7.9 & 8 \\
$6-6.5$ & 6.2 & 6.3 & 6 \\
$5.5-6$ & 4.8 & 4.8 & 5 \\
$5-5.5$ & 3.9 & 3.2 & 4 \\
\hline
\end{tabular}

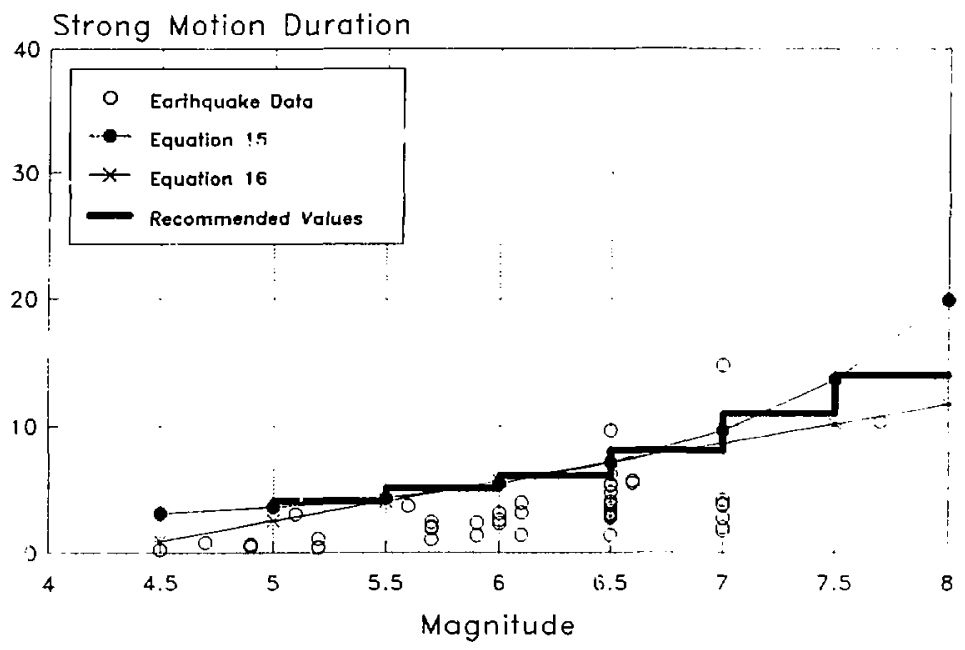

Figure 10 Recommended $T_{D}$ vs. Magnitude 
Table 4

Duration Envelope Function Parameters vs. Earthquake Magnilude

\begin{tabular}{|c|c|c|c|c|c|}
\hline Magnitude & $\begin{array}{l}\text { from } \\
\mathrm{Eq} .17\end{array}$ & $\begin{array}{l}t_{\text {n. }} \text { from } \\
\text { Eq. } 18 \\
\end{array}$ & $\begin{array}{c}\text { Time of Maximum } \\
\text { Power, } t_{m}\end{array}$ & $\begin{array}{c}\text { Rise Time, } \\
t_{\mathrm{e}}\end{array}$ & $\begin{array}{c}\text { Decay Time, } \\
y \\
\end{array}$ \\
\hline $\begin{array}{l}7.5-8 \\
?-7.5 \\
6.5-7 \\
6-6.5 \\
5.5-6 \\
5-5.5\end{array}$ & $\begin{array}{l}18.6 \\
13.0 \\
9.3 \\
6.9 \\
5.3 \\
4.3\end{array}$ & $\begin{array}{l}12.1 \\
10.4 \\
8.7 \\
7.0 \\
5.3 \\
3.6\end{array}$ & $\begin{array}{l}15 \\
12 \\
9 \\
7 \\
5 \\
4\end{array}$ & $\begin{array}{c}2 \\
2 \\
1.5 \\
1 \\
1 \\
0.5\end{array}$ & $\begin{array}{l}11 \\
9 \\
7 \\
5 \\
4 \\
3\end{array}$ \\
\hline
\end{tabular}

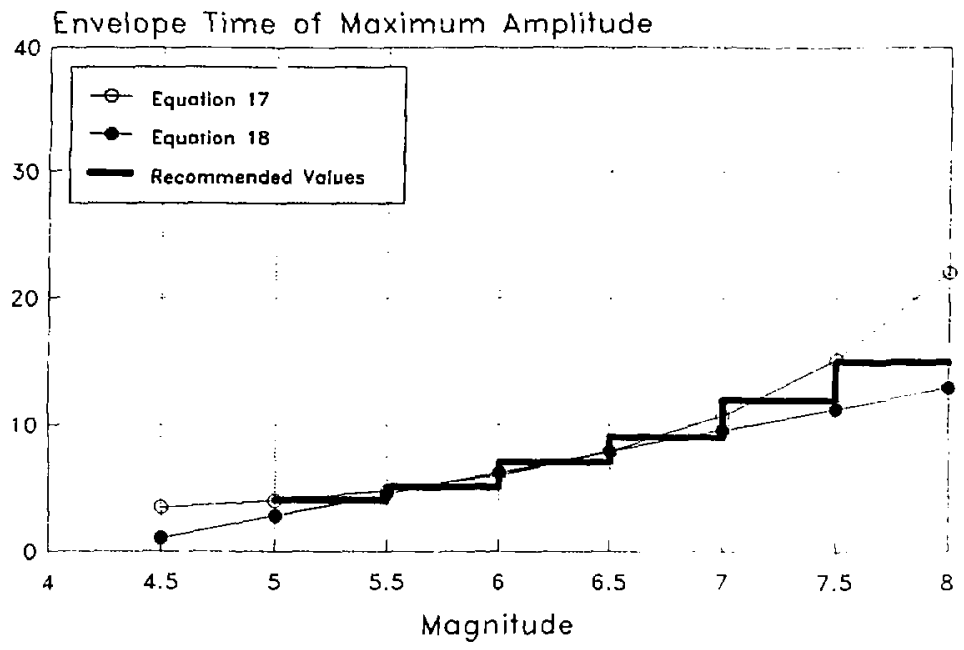

Figure 11 Recommended Duration Envelope Function

Tinue of Maximum Amplitude, $t_{\alpha}$, vs. Magnitude 


\section{References}

1. Bernreuter, D.L., Seismic Magnitude/Duration, NUREG/CR-5503, U.S. Nuclear Regulatory Commission, Washington, DC., July, 1989.

2. Boore, D.M., and Joyner, W.B., "The Empirical Prediction of Ground Motion," Bulletin of he Seismological Socjety of America, Vol. 72, No. 6, pp. S43-S60, December 1982.

3. Bolt, B.A., "Duration of Strong Ground Motion", Proceedings of the Sth World Conference on Earthquake Engineering, Rome, 6-D, Paper No. 292

4. Campbell, K.W., "Near-Source Attenuation of Peak Horizontal Acceleration," Bulletin of the Seismological Society of America, Vo! 71, No. 6, np. 2039-2070, December 1981.

5. Dobry, R., ldriss, I.M., and Ng, E., "Duration Characteristics of Horizontal Components of Strong-Motion Earthquake Records," Bulletin of the Seismological Society of America, Vol. 68, No. 5, pp.1487-1520, October 1978.

6. Housner, G.., "Intensity of Earthquake Ground Shaking Near the Causative Fault," Proceedings of the 3 rd World Conference on Eanhquake Engineering, New Zealand, Volume 3 , $94112,1965$.

7. Kawashima, K., and Aizawa, K., "Bracketed and Normalized Duration of Earthquake Ground Acceleration", Earthquake Engineering and Structural Dynamics, Vol. 18, 1041-1051, 1989.

8. Kennedy, R.P., et. al., Engineering Characterization of Ground Motion - Task I: Erfects of Characteristics of Free-Field Motion on Structural Response, NUREG/CR-3805. U.S. Nuclear Regulatory Commission, Washington, DC, May 1984.

9. Krinitzksy, E.L, Chang, F.K., and Nutli, O.W., "Magnitude-Related Earthquake Ground Motions", Bulletin oi ile Association of Engineering Geologists, Vol. XXV, No. 4, pp. 399-423, 1988.

10. McCann, M.W, and Shah, H.C., RMS Acceleration and Duration of Strong Ground Motion. Report No. 46, The John A. Blume Earthquake Fngineering Center, Department of Civil Engineering, Stanford University, October 1980.

11. Philippacopoulos, A.J., Recommendations for Resolution of Public Comments on USI A-40, "Seismic Design Criteria", NUREG/CR-5347, U.S. Nuclear Regulatory Commission. Washington, DC, June 1989.

12. Maurice Power, Personal Communication, Geomatrix Consultants, San Francisco, CA. . November, 1991.

13. Shaukut, S.K., and Chokshi, N.C., Regulatory Analysis Tor USI A-40, "Scismic Design Criteria", NUREG-1233, U.S. Nuclear Regulatory Conınission, Washington, DC. Seplember 1989.

14. Walter Silva, Personal Communication, Pacific Engineering and Analysis. EI Cerrito, CA. November, 1991.

15. Theofanopulos, N.A., Watabe, M., and Matsukawa, "Strong Motion Duration and Intensity Function", In Proceedings of 9th SMiRT, Vol. KI, pp. 31-26. 1987. 
16. Theofanopulos, N.A., and Watabe, M., "A New Definition of Strong Motion Duration and Comparison with Other Definitions", Structural Engineering/Earthquake Engineering, Vol. 6 , No. 1, 11ls-122s, April 1989.

17. Trifunac, M.D., and Brady, A.G., "A Study on the Duration of Strong Earthquake Ground Motion," Bulletin of the Seismological Society of America, Vol. 65, No. 3, pp. 581-626, June, 1975.

18. Trifunac, M.D., and Westermo B.D., "Dependence of the Duration of Strong Earthquake Ground Motion on Magnitude, Epicentral Distance, Geologic Conditions oat the Recording Station and Frequency of Motion", University of Southern California, Department of Civil Engineering Report No. CE 76-02, November, 1976.

19. Vanmarcke, E.H., and Lai, S.P., "Strong-Motion Duration and RMS Amplitude of Earthquake Records," Bulletin of the Seismological Society of America, Vol. 70, No. $\$$, pp. 1293-1207, August 1980.

20. Westermo B.D., and Trifunac, M.D., "Correlations of the Frequency Dependent Duration of Strong Eanthuake Ground Motion with the Magnitude, Epicentral Distance, and the Depth of Sediments at the Recording Site", University of Southern California, Deparment of Civil Engitseering Report No. CE 78-12, September 1978.

21. Geomatrix Consultants, "Evaluation of Effective Acceleration and Selection of Seismic Analysis Accelerograms for Lawrence Livermore National Laboratory, "Project No. 1587.01. March 1991 . 


\section{Appendix \\ Evaluation of Duration Parameters from Envelope Function}

Consider a duration envelope function such as that shown in Figure 2 but with maximum acceleration amplitude of $A_{m}$ (Fig. 2 has maximum amplitude of unity) and where $t_{r}=(\therefore / 7) t_{m}$ and $t_{d}=(5 / 7) t_{d}$. For such a duration envelope function, it may be shown that the cumulative energy by Eq. 2, through time, $t$, is:

for $0 \leq t \leq t$.

$$
E(t)=\frac{A_{m}^{2}}{3 t^{2}} t^{3}
$$

for $\mathrm{t}_{\mathrm{r}} \leq \mathrm{t} \leq \mathrm{t}_{\mathrm{r}}+\mathrm{t}_{\mathrm{m}}$

$$
E(t)=E(1,)+\lambda_{m}^{2}\left(t-t_{s}\right)
$$

for $t_{f}+t_{m} \leq t \leq t_{r}+t_{m}+t_{d}$

$$
E(1)=E\left(t_{r}+t_{m}\right)+A_{m}^{2}\left(t-\frac{t^{2}}{t_{a}}+\frac{t^{-3}}{3 t_{d}^{2}}\right)
$$

where $t=t-\left(t_{t}+t_{m}\right)$

By these relations, the total cumulative energy for a record is:

$$
E_{m}=E\left(t_{t}+t_{m}+t_{d}\right)=A_{m}^{2}\left(t_{t} / 3\right)+A_{m}^{2}\left(t_{m}\right)+1_{m}^{2}\left(t_{d} / 3\right)
$$

or $E_{m}=(9 / 7) A_{m}^{2} t_{m}=1.286 A_{m}^{2} t_{m}$

The cumulative energy at $t=t_{r}$, and $t=t_{r}+t_{m}$ and at $5 \%, 75 \%$, and $95 \%$ of the total cumulative energy are:

$$
\begin{aligned}
& E\left(t_{r}\right)=A_{m}^{2}(1 / 7) t_{m} / 3=0.048 A_{m}^{2} t_{m} \\
& E\left(t_{r}+t_{m}\right)=0.048 A_{m}^{2} t_{m}+\lambda_{m}^{2} t_{m}=1.048 A_{m}^{2} t_{m} \\
& E_{5 *}=0.05(1.286) A_{m}^{2} t_{m}=0.064 A_{m}^{2} t_{m} \\
& E_{75 *}=0.75(1.286) A_{m}^{2} t_{m}=0.964 A_{m}^{2} t_{m} \\
& E_{95 *}=0.95(1.286) A_{m}^{2} t_{m}=1.221 A_{m}^{2} t_{m}
\end{aligned}
$$

Therefore, for this shape duration envelope function, $t_{0,05}$ and $t_{0 . s s}$ fall within the constant amplitude region and $t_{0.95}$ falls within the decay region. $t_{0.05} b_{0.75}$, and $t_{0} 4.5$ are the times at which $E_{0.0 s}$. $E_{0} \ldots$. and $E_{0.9 s}$ are reached, respectively. Where $t_{\mathrm{s}}=(1 / 7) \mathrm{t}_{\mathrm{m}}=0.143 \mathrm{t}_{\mathrm{m}}, \mathrm{t}_{\mathrm{r}}+\mathrm{t}_{\mathrm{m}}=1.143 \mathrm{t}_{\mathrm{m}}$, and $\mathrm{t}_{\mathrm{r}}+\mathrm{i}_{\mathrm{m}}$ $+t_{d}=1.143 t_{m}+(57) t_{m}=1.857 t_{m}, b_{0.05}, b_{0.75}$, and $t_{0.95}$ may be calculated in the manner presented below. 
From Equations A-1b, A-3, and A-5, $h_{0.05}$ is:

$$
\begin{aligned}
& 0.064 A_{m}^{2} t_{m}=0.048 A_{m}^{2} t_{m}+A_{m}^{2}\left(t_{0.05}-(1 / 7) t_{m}\right) \\
& t_{0.05}=0.064 t_{m}-0.048 t_{m}+(1 / 7) t_{m}=0.159 t_{m}
\end{aligned}
$$

From Equations $A-1 b, A-3$, and $A-6, L_{0.75}$ is:

$$
\begin{aligned}
& 0.964 A_{m}^{2} t_{m}=0.048 A_{m}^{2} t_{m}+A_{m}^{2}\left(t_{0.75}-(1 / 7) t_{m}\right) \\
& t_{0.75}=0.964 t_{m}-0.048 t_{m}+(1 / 7) t_{m}=1.059 t_{m}
\end{aligned}
$$

From Equations A-1c, $A-4$, and A-7, $\iota_{0.9 s}$ can be obtained from:

$$
\begin{aligned}
& 1.221 A_{m}^{2} t_{m}=1.048 A_{m}^{2} t_{m}+A_{m}^{2}\left(t_{0.95}-\frac{t_{0.05}^{-2}}{(5 / 7) t_{m}}+\frac{t_{0.05}^{3}}{3\left(5 / 7 t_{m}\right)^{2}}\right) \\
& :_{0.95}^{-3}-2.144 t_{m} t_{0.95}^{-2}+1.531 t_{m}^{2} t_{0.95}-0.265 t_{m}^{3}=0 \\
& \text { where } t_{0.85}=t_{0.95}+1.143 t_{m}
\end{aligned}
$$

The cubic equation for $t_{0.95}^{\prime}$ may be solved from relations given in mathematical handbooks or by trial and error to give:

$$
\begin{aligned}
& t_{0.85}=0.251 t_{\mathrm{m}} \\
& \therefore t_{0.85}=1.39+t_{\mathrm{m}}
\end{aligned}
$$

From $t_{0.05}, t_{0.75}$, and $t_{0.95}$, strong motion duration by the Trifunac-Brady definition, $T_{T \cdot s}$, and by the NUREG/CR-5347 definition, $T_{D}$, are:

$$
\begin{aligned}
& T_{T-\theta}=1.394 t_{\mathrm{m}}-0.159 t_{\mathrm{m}}=1.235 t_{\mathrm{m}} \\
& T_{D}=1.059 t_{\mathrm{m}}-0.159 t_{\mathrm{m}}=0.900 t_{\mathrm{m}}
\end{aligned}
$$

The Vanmarcke-Lai strong motion duration definition is the time over which the entire energy of the earthquake record, $E_{m}$, is uniformly distributed. From Eq. A-2, this energy is $1.286 \mathrm{~A}_{\mathrm{m}}{ }^{2} \mathrm{t}_{\mathrm{m}}$. The time over which this energy is uniformly distributed may be Jetermined from Eq. A-1 $\mathrm{b}$, as $\mathrm{E}_{\mathrm{m}}$ $=A_{m}{ }^{2} S_{0}$. Serting these two expressions for $E_{m}$ equal to each other gives $S_{0}=1.286 t_{m}$. 